\title{
Improving Tourist Offer Through Inter-Destination \\ Cooperation in a Tourist Region
}

\author{
Vaso Jegdić \\ Faculty of Sport and Tourism \\ University of Educons \\ Radnička Street 30a \\ 21000 Novi Sad, Serbia \\ E-mail: vaso.jegdic@tims.edu.rs \\ Dragica Tomka \\ Faculty of Sport and Tourism \\ University of Educons \\ Radnička Street 30a \\ 21000 Novi Sad \\ Serbia \\ E-mail: drtomka@tims.edu.rs \\ Mladen Knežević \\ Faculty of tourizm \\ University in Maribor \\ Cesta prvih borcev 36 \\ (SI)-8250 Brežice \\ Slovenia \\ E-mail: mladen.knezevic@um.si \\ Marko Koščak \\ Faculty of Tourizm \\ University in Maribor \\ Cesta prvih borcev 36 \\ (SI)-8250 Brežice
}




\author{
Slovenia \\ Email: marko.koscak@um.si \\ Srdjan Milošević (Corresponding author) \\ Faculty of Sport and Tourism \\ University of Educons \\ Radnička Street 30a \\ 21000 Novi Sad \\ Serbia \\ E-mail: srdjan.milosevic@tims.edu.rs \\ Iva Škrbić \\ Faculty of Sport and Tourism \\ University of Educons \\ Radnička Street 30a \\ 21000 Novi Sad \\ Serbia \\ E-mail: iva@tims.edu.rs \\ Ksenija Keča \\ Libertas Business College \\ Trg J. F. Kennedy 6b \\ 10000 Zagreb \\ Croatia \\ E-mail:kkeca@libertas.hr
}

Received: September 16, 2015 Accepted: October 27, 2015 Published: December 24, 2015

doi:10.5296/ijrd.v3i1.8304

URL: http://dx.doi.org/10.5296/ijrd.v3i1.8304

\begin{abstract}
Modern development of tourism is under a strong influence of globalisation processes. In order to achieve global competitiveness, it is necessary to build regional competitiveness due to the significant role of the region as the basic unit of development and as the carrier of
\end{abstract}


tourist offer that should satisfy globalised demands in terms of both quantity and quality. Up until now, the destinations built competitive advantage through shaping local resources and possibilities into products and services for the visitors, and through coordinating activities of various participants on the level of the destination. Today, it is known that the destinations that aim towards leadership positions in the market must seek new sources of competitive advantage, considering that efficient cooperation of interested parties within a destination does not always suffice. One of such advantages is the development of cooperation amongst destinations and their linkage into wider tourist regions. In other works from the subject area, several forms of inter-destination cooperation and its factors of influence have been identified. However, even until now, this subject has not been sufficiently clarified. The subject of the research is the cooperation amongst destinations within a wider tourist region and the possibilities for improvement of the tourist offer through such cooperation. The aim of the research is to determine the validity of activities of inter-destination cooperation within a wider tourist region. General analytic-synthetic method of research was used in the paper, in the span of bibliographic-speculative to empirical approach by applying the method of document content analysis.

Keywords: Inter-destination cooperation, Tourist region, Globalisation processes, Competitive advantage, Content analysis.

\section{Introduction}

Tourist destinations can be considered complex networks that, from the standpoint of supply, include a large number of participants who deliver various products and services in interpersonal cooperation (see: Gunn, 1994; Buhalis, 2000; Beritelli, 2011; Fyall et al., 2012; Beritelli et al., 2014). From the standpoint of the tourist, destination is seen as a unique whole, a place where integral tourist product or destination impression is realised. As stated by Buhalis: "Destinations are amalgams of tourist products that offer integrated experience for the consumers" (2000, p. 97). World Tourism Organisation (UNWTO, 2002) points out that “(...) local tourist destinations contain various groups of interest, frequently including the local community, and can represent the outcome and business network for forming larger destinations."

The development of a destination is a complex phenomenon that demands activities on several levels. Therefore, it demands to tackle the issues (1) on the level of individual subject - business, public, social, (2) on the level of the destination-company interaction, authority, DMO and other participants, and (3) on the level of larger geographic or regional area amongst destinations (see: Haugland et al., 2001).

Primarily, destinations should develop the ability to form resources and authority, distributed through a large number of subjects, into products and services on the level of the destination. The fact that the product is formed on destination level, and that resources and competencies are owned by individual subjects, forces those subjects to interlink their resources and competencies to create a destination product or "integrated consumer experience". The main issues are related to attractions management, building of infrastructure or receptive base, as well as the development of entrepreneurship in the area of tourist offer. Innovations and 
entrepreneurship secure basic requirements for the development of local tourist product. Most of the innovation focus is on the products and methods of production (Nelson et al., 2006), although innovations can also be guided by new market demand that generates entrepreneur initiatives (Hjalager, 2010). The idea of a destination as an entity is not of great value if all companies and other participants only deal with organisation image in their communication with the clients. An important task for all destinations is to develop a joint and consistent image, and to efficiently transfer it onto the market (Buhalis, 2000).

Secondly, the destination is the framework for forming an integral tourist product. Individual participants should function as a wholesome system, which demands coordination of activities and management of tourism on the level of the destination. Various models of cooperation are applied in areas such as marketing, reservations or acquisition, as well as the integration of local networks (see Haugland et al., 2011). The destinations choose basic strategic operations to create a portfolio of their tourist product, where they can primarily decide to concentrate or diversify their tourist product, which means diversification in relation to whether the focus is on the development of niche or mass tourist products, in accordance with the desired market size and physical volume of development (Benur \& Bramwell, 2015). Intensively developed and used tourist products are conventionally labelled as mass tourism (Vainikka, 2013). A well-balanced portfolio, amongst other things, serves to alleviate seasonality. When the destination portfolio is limited in volume and depends on weather conditions, it will inevitably result in the problem of seasonality. Especially significant are the strategic options that destinations apply to connect tourist product into a wholesome system of offer. It is necessary to emphasise the significance of cooperation amongst participants and institutionalised support in stimulating networking, transfer of knowledge and the best practices in local destinations. The cooperation of interested parties within destinations is recognised as one of the most important factors for the success of a destination (e.g. Wang, 2008, Jegdić \& Marković, 2010; Beritelli, 2011). To grasp the complexity of managing a tourist destination, the concept of tourism networks has seen a rise in popularity during the last decade (see: Scot et al., 2008; Baggio, 2008; van der Zee \& Vanneste, 2015). Hall (2005: 179) defines a network as "an arrangement of interorganisation cooperation and collaboration". In literature, several positive values are attributed to tourism networks. In general, benefits of networked collaboration are suggested to entail the creation and diffusion of knowledge and innovation, quality improvement of tourism product offering, a higher quality of service provision, a more efficient production process, an increasing sustainability of the destination and in total a more competitive destination (van der Zee \& Vanneste, 2015, p. 52).

The third segment, that primarily concerns further deliberations in this paper, is focused on the connection between two or more individual destinations. Efficient cooperation within a destination no longer guarantees a secure competitive advantage. Implementation of cooperation between destinations can be one of the potential sources of competitive advantage on the modern tourist market, and it refers to the exchange and spreading of information and knowledge on the entire area as well as creating larger spatial-functional wholes-touristic regions. Inter-destinational connections can be an instrument in strategic 
development of a destination through identifying and expanding good practice and avoiding problems, which promotes imitation and innovation in the area. The exchange of information amongst destinations does not necessarily lead to imitation, as their experiences are not necessarily similar due to the access to different resource bases (natural, human, organisational, public, etc.) However, new information can be translated into new knowledge that can lead to innovations depending on the absorption capacity of the participants (Cohen \& Levinthal, 1990). According to Fyall et al. (2012: 20), "inter-destination cooperation can include neighbouring destinations, but also remote destinations, where the connection is, in that case, established based on a mutual form of niche tourism as is gastronomic tourism, or based on linear geographic object such as traders route or a big river". Eventually, these wholes can encompass several states (the Alps), or even several continents (the Mediterranean). In this way, tourist destinations as networks begin to participate in network cooperation. Regions become key subjects, relations of regions and local level are formalised, globally strong destinations usually have bigger autonomy, yet they remain in the system of tourist regions (Horwath HTL Zagreb, 2013).

\section{Inter-Destination Cooperation}

Even though the significance of inter-destination cooperation is recognised (e.g. Henderson, 2001; Naipaul et al., 2009; Fiall et al., 2012; Vang et al., 2013; Zemla, 2014), this phenomenon has not yet been analysed in depth, as is the case, for example, with regard to cooperation between the actors within local destinations. Tourist marketing has become the cornerstone for strengthening the position of regions in the global tourist market (Stratigea et al., 2008: 315). The same author points out that ICTs have enhanced the marketing potential of regions as tourist destinations, as well their role in networks for the implementation of a successful e-marketing strategy. In applying the concept of the digital business ecosystem to the tourism sector, Del Chiappa and Baggio (2015) defined a tourism destination as a networked system of stakeholders delivering services to tourists, complemented by a technological infrastructure aimed at creating a digital environment that supports cooperation, knowledge sharing, and open innovation. Networks are proposed to function as systems which can organise and integrate tourism destinations, create benefits for participating tourism firms, enhance destination performance and quality and stimulate the provision of "wholesome and memorable experiences" for tourists ( Zach \& Racherla, 2011: 98). In this way, networking participants within the destination, with the application of ICTs and e-marketing, can unite fragmented tourist offer of local destinations, and finally provide an overall tourism product in the region.

According to Mariani and Kylanen (2012), coopetitive (coopetition= cooperative competition) strategies and relations are becoming more suitable for modern economic environment as they allow individual tourist companies and destinations to establish balance between cooperation and competition. As a consequence, destinations are more prone to establishing coopetitive than competitive advantage. More precisely, competing companies located in a certain region, usually want to also cooperate for marketing purposes to improve the attractiveness of the region, and with that improve the attractiveness of their destination. Similar situation is with destinations, which can also compete and cooperate at the same time. 
According to Mariani et al. (2014), tourist destinations, just like companies, should carefully take into consideration the advantages and the costs that result from specific coopetitive relations that they initiate, nurse and maintain, and that process should be repeated over time. Once established relations of cooperation can be mixed with competition and changed at every given moment.

According to Prideaux and Cooper (2002), too much competition between destinations in a region weakens the overall efficiency and effectiveness of regional tourism development. Operating on markets different from the destination demands the ability to cooperate with the neighbour on one market and compete with them in the other. What makes this relationship more complex is the fact that destinations, restricted by the aim to secure better perspective for themselves, do not reflect the perspective of individual visitors. The aim of tourists is to maximise their gain by grouping various destinations across the region before they limit themselves to a section of the region/destination (Hwang \& Fesenmaier, 2003; Naipul et al., 2009). The fact that the visitors during their stay in a destination will frequently visit neighbouring areas does not necessarily have to be a threat, but it can also be a convenience for the destination (Wang et al., 2013). This increases the demand that destinations are led less by "boarder restrictions" and more "led by demand" (Beritelli et al., 2007). This attitude is widely accepted in tourist literature as a support towards the tendency of the passengers for multi-destination travels (Puczko et al., 2007).

Secondly, it is known that, in the context of regional tourism, tourist product can be observed as a complex product, where each of the components is delivered by individual tourist companies located in various destinations in the region (Hall, 1999). However, as there is a problem of determining borders with companies (outsourcing and resource dependence), such problem also exists with destinations due to their hierarchal structure and different perceptions of users of destination product. Apart from that, destination product is created not only by internal companies, but also by foreign participants. Some of them, such as are investors, have stable connections with the destination, however, there are many actors that only temporarily participate in product formation or in marketing of a destination. This group includes "tour operators and companies such as breweries, sport equipment manufacturers and others that conduct joint promotional campaign for a destination" (Zemla, 2010: 262). In some cases, it is possible that they only participate with a destination as a whole, but they can also cooperate with certain companies. Buhalis (2000) states that most destinations consist of tourist distributor networks. In practice, many tourist companies and destinations can, at the same time, participate in more than one network. This makes the matter of competition and cooperation between destinations even more complex. Many authors, instead of company and destination competitiveness advocate the analysis of competitiveness of business networks (e.g. Provan et al., 2007; Zemla, 2010; Scott et al., 2011).

It is possible to identify numerous reasons for cooperation of destinations with their neighbours. Probably the most significant one being the creation of spatially larger tourist region that is more attractive to tourists (Wang et al., 2013). Apart from that, there are other reasons such as improving product portfolio, cost reduction and increase of market campaign efficiency (Naipaul et al., 2009). According to Fyall et al. (2012), inter-destination as well as 
intra-destination cooperation can be observed twofold, as organic or as mediated (by DMO). The first situation occurs when there is cooperation independent from wider destination strategy conducted by DMO. These authors point out that mediated cooperation, inter and intra-destination, is increasingly more desirable and state that cooperation within a destination is a necessary, but not sufficient condition to achieve its goals; cooperation with other destinations is also necessary. Moreover, efficient cooperation within destinations can be treated as a prerequisite for successful inter-destination cooperation.

Zemla (2014) finds that conducting inter-destination cooperation is more difficult and demanding than establishing intra-destination connections. It creates the possibility for several significant challenges in the development and the maintenance of such long-term partnerships that include different priorities, different marketing directions and limited resources. A higher risk is present with international cooperation of destinations as it raises the question of legitimacy and prestige of participants in the cooperation outside the borders of own destination, i.e. own country. Several examples from practice can be listed that illustrate how different destinations cooperate with their neighbours. Such cooperation is undertaken in various forms and it should aided in the realisation of different aims. Naipaul et al. (2009) point out that cooperation on a regional level is a very tempting solution for small neighbouring destination with limited tourist product and resources.

In the works from this area, several forms of inter-destination cooperation have been identified, as well as the factors that influence their choice. These factors include the nature of the tourist product, international character of cooperation, consumer perception of tourist regions, the size and level of administrative divide in the country of the cooperative destination, the number of cooperative destinations, and the formality of cooperation (Zemla, 2014: 251). One of the largest limiting factors for cooperation is the existence of transport barriers between destinations. In addition to this, the digital divide aspect might also be a strong barrier.

Researchers often touches upon the issue of cooperation determinants in tourism. However, despite their influence and complex nature, cooperation determinants are rarely the only subject of research and are often presented indirectly. What is also lacking is a clear typology of cooperation determinants. All of the named theories of cooperation adds to this issue a rather narrow perspective. In this research, integrative approach was used that relies on previous research results in order to build a conceptual frame for the classification of cooperation determinants between destinations. Cooperation determinants in a tourist region can be understood as different kinds of circumstances - situations, events, facilities, characteristics, possibilities of the participants etc., that determine the readiness to begin cooperation (Wood \& Gray, 1991). In general, four approaches are listed: analysing the cooperation determinants as a prerequisite for cooperation, factors crucial for a successful development of cooperation, key personal abilities necessary for managing cooperation in tourism, and factors of cooperation effectiveness. Perhaps the largest set of cooperation determinants, in their role as prerequisites, are suggested by Fyall and Garrod (2005), characterising them as starters of cooperation. They point to such different factors as globalisation, international political and trading agreements, stockholder limitations, 
consolidation and concentration of economic power, public financing, technological progress, growth of tourist demand, strategic alliances, increased competition or increased consumer expectation.

Katarzyna Czernek (2013) built a conceptual frame for the classification of cooperation determinants in a tourist region. The main criteria for division are the source and the volume of the determinant phenomenon and the level of the influence of the destination/region on the phenomenon. In this frame, Czernek separated two wide groups of determinants: exogenous and endogenous, that are further divided into economic, socio-cultural, demographic, legal, political and geographic. Exogenous (foreign) determinants are concerned with larger territorial systems than region: countries, groups of countries, or even the world. Individual actors in tourist region have a small, often no influence on these determinants. On the contrary, endogenous (inner, regional) determinants are mostly generated within the region, where they are the most visible. These factors are a result of direct and frequent contacts between participants: potential or existing partners. The subjects from the region have a relatively stronger influence on these groups of determiners than they have on exogenous factors. The author also states that, in one context, individual determinants can encourage, and in another, hinder the cooperation of stakeholders in a tourist region.

The literature also identifies numerous factors that influence cooperation in tourist regions in post-transitional countries (e.g. Roberts \& Simpson, 2000; Tosun, 2000). What is significant is that many of them present an obstacle for cooperation of interest groups in a tourist region. For example, such are: underdeveloped civil society, insufficient experience in cooperation and the lack of positive examples to follow, adaptive (recreational) instead of proactive attitudes towards cooperation, financial problems of the local government etc. It can be assumed that there are cooperation determinants specific for individual countries, especially for countries in transit. This also refers to Serbia, where cooperation in the area of tourism has a very short history that began only with the transformation of the economic system of the country in the previous and the beginning of this century.

\section{Research Method}

The aim of the research is to understand the nature and validity of the activities of inter-destination cooperation. Considering such aim, the approach of qualitative case study was applied (Yin, 1989). Qualitative research attempts to communicate the knowledge related to interpretive and evaluative knowledge (Creswell, 1994) and is especially suitable to study little known phenomena. According to Burns (2000: 13), "qualitative research plays an important role of suggesting possible relationships, causes, effects and dynamic processes". Hughes Ch. points out that qualitative research is the method of choice when the research question requires an understanding of processes, events and relationships in the context of the social situation (www. csse.monash.edu.au/ smarkham/ resources/ qual:htm). General analytical-synthetic method of research is used in the paper, with the application of document content analysis technique. Qualitative, or non frequency-sensitive content analysis, identifies trends and latent features of messages in the document content by identifying semantic layers. 
As a basis for analysis of the content, the project of linking regional destination organizations in Slovenia was used.

\section{Research Results and Discussion}

\subsection{Some Basics of Inter-Destination Cooperation in Slovenia}

In accordance with the aim of the research, an insight has been made into the planned measures and forms of inter-destination cooperation in the area of the Republic of Slovenia. We decided for the analysis of some Slovenian experiences for two reasons. First being the perennial fruitful cooperation with some academic institutions from Slovenia from the area of tourism, which enabled a somewhat easier access to paperwork and experiences. The second reason is the position of Slovenia as a member of the European Union, where processes of inter-destination cooperation appear within a wider tourist region.

The analysis was conducted based on document analysis, using the technique of content analysis. As a basis for analysis of the content, a long-term project with a prominent goal was used i.e. one with the intention for a more intensive connection of regional destination organisations in the period of 2014-2020. Project coordinator was the Slovenia Tourist Board, and it encompasses 13 regional developmental organisations in Slovenia as well as some public offices such as the institutions for tourism in Ljubljana and Maribor.

\subsection{Foundations for Designing the Entire Project}

The project finds its foundations in two documents. First are the documents of the European Cohesion Fund 2014-2020 (European Commission, 2014), and the second foundation is the Strategy of Slovenian tourism from the year 2007 that, already at that time, defined inter-regional connecting as an important task (Ministry of Economy, 2007). The strategy of the year 2007 implements the necessity of inter-destination connecting and cooperation, however, that regional destination organisation does not become a new administrative structure, or a new organisational body, but it only changes the form of its functioning. From these documents, basic developmental aims of the project up to the year 2020 were taken. The most general aim was stated to be "to encourage entrepreneurship by enabling easier economic use of new ideas and to encourage the foundation of new companies" (Project draft, 2014). As it is visible from the formulation, it is a completely generalised aim that is focused on general conditions of business that apply to all areas of economic development, not only to tourist development. In that context, special emphasis is placed on the development of small and medium sized businesses, goal that was especially interesting to the previous administration of the European Committee, and it seems that it remains a "mantra" in the institutions of the committee. In order to develop that initiative, it was necessary to operationalise it within the programme, which was done through two specific goals, encouraging the foundation and operation of businesses, foremost of the start-up business, and through the increase of additional value of small and medium sized businesses. Of course, it is necessary to note that the operative programme that "inspired" the Slovenian project originated during the ending of a crisis, so the goals were not derived from the needs of tourist industry, but from a delayed reaction to the crisis (or a possible fear of a new crisis), 
which is why the authors' peak of creativity is in the creation of new businesses (read: new workplaces), without thinking about the specificities of tourist development. That is why the project of inter-destination cooperation is founded on an economic mantra to create new small and medium sized business, and not on the specificities of tourist activity in a wider sense, from which they could derive forms and contents of inter-designation cooperation. It is probably because of such generally formulated reasons why the initiators for a real cooperation of this kind are still none-existent in reality, and instead it all remained on project documentation.

\subsection{Defining the Purpose of the Project}

Promoting individual tourist regions under a common mark of Slovenia as a tourist destination was listed to be the basic purpose of this project. If there were an attempt to interpret such formulated purpose of the project, then it could be claimed that the final goal is reduced to the consolidation of individual tourist regions into a common national brand, which is probably only a single, and not the most important, aim of inter-destination cooperation. The second mentioned purpose of this research was the creation of a firm partnership web that would be more recognisable in the processes of introduction in domestic and foreign markets (Project draft, 2014), which is in fact only a subvariant of the first formulation of purpose and probably does not contribute in greater measure to the development of inter-destination cooperation. By closely explaining the purpose of the project, authors state that during the realisation they will "uphold the principles of maintainable development of tourism, secure suitable business environment and achieve a higher quality that will enable competitiveness of Slovenian tourism with more efficient and innovative activity in the market and promote Slovenia as a tourist destination" (Project draft, 2014), whereas in the project design itself clearly stated necessary operational elements were not listed, so such approach could be called "project economy", meaning all those formulations that do not have their own operational apparatus as they are focused on achieving success in a contest add to which the project is applied, and not on the realisation of the content of the project itself.

\subsection{Defining the Aim of the Project}

The authors of the project list the promotion of tourist offer and establishing a firm partnership network as a general aim. The realisation of all aims is planned by a joint promotion in fairs and similar larger events, which again reduces inter-destination cooperation to a marketing function, which is logical considering the formulation of the purpose of the entire project. Although some authors claim that precisely marketing is the basis of the development of inter-destination cooperation (Naipaul et al., 2009), that cooperation cannot be reduced solely to marketing and especially not if it is not based on modern information technologies and wide possibilities that it offers (see: Stratigea et al., 2008; Del Chiappa \& Baggio, 2015).

Apart from that, several general aims are listed, such as recognisability of tourist products, achieving a higher level of quality of tourist products and offer, and maintainable tourist development. Apart for these, almost declaratively presented aims, two goals are listed that 
could in fact be signified as serious attempts to establish inter-destination cooperation. Those elements are "precisely defining the vision, aims and guidelines of development up to the year 2020", and on those elements it is possible to build operationally significant elements of inter-destination cooperation (Project draft, 2014). From the messages of a number of authors, it is known that for a successful inter-destination cooperation firm initiators of action must exist (Fyall \& Garrod, 2005; Czernek, 2013; Zemla, 2014) that are not only a list of wishes but are relevant determinants of development of all regions that participate in that cooperation. The perception of potential benefits to be gained is the key point of cooperation. That is why the first inhibitor to be overcome at the beginning of the cooperation process is proper understanding of the reasons, aims and benefits to be obtained from the cooperation, as well as costs and involvement barriers to deal with. Among the factors that are mentioned in the literature as obstacles to cooperation (Chernek, 2013), the following can be pointed out here: underdeveloped civil society, insufficient experience in cooperation and the lack of positive examples to follow. It is necessary to point out that not even in the formulation of the project purpose, nor in the formulation of its aims, creators of the project did not begin from the entry marked as significant with many authors, which is intra-destination cooperation as a prerequisite for inter-destination cooperation (Zemla, 2014). As networks can enhance the cooperation of all stakeholders in tourism destinations, they can unite existing fragmented tourist offer and finally ensure the overall tourism product, which is exactly what is necessary in the case of Slovenia. There are no worthy mentions of that dimension in the project draft.

\subsection{Planned Activities}

According to research design, three key activities are planned in the development of the project itself. The first activity is quality improvement of the existent and the development of new tourist products. It can be said that it is an activity that fits perfectly into the innovation scheme. (Nelson et al., 2006), and therefore it is in the very foundations of inter-destination cooperation (Zemla, 2014). At the same time, it is necessary to point out that most authors that deal with inter-destination cooperation do not rely factors of cooperation development only on the participants from the tourist sector, but also mention other important factors such as academic community and its contribution to that development (which is given primary importance by Zemla), then of course, companies (tourist), executive office, while other authors also attribute civil organisations as highly important factors. Although, as it was already mentioned, the element of innovativeness with all its consequences is highly significant in this process, authors of the plan practically reduce the participants in that process to the narrowest elements of tourist activity (development organisations), and most of the other participants are simply excluded from the blueprints of those processes, so it raises the question up to which level is that change even possible. It is necessary to especially point out the academic community that has an increasingly larger base in Slovenia and ever more competent scientific and practical potentials. It has been over 20 years since the foundation of the first college in the area of tourism, and the cooperation between tourist industry and universities is still in a very limited scope, and in practice it has not gone much further than "letters of intention". On the other hand, research shows that two functions of the scientific community are important in the development of tourism: 1. development of fundamental 
knowledge and 2. development and progress of industrially relevant technology (Alfonso et al., 2010). To exclude the academic community from developmental processes is in fact to exclude knowledge and technology, but also to limit dynamics of development as probably the most important function of the academic community is a constant vigilance of changes and development.

These claims are also relevant for the other planned activity, which is the activity of promotion and placement of tourist offer into the market. Promotion, as well as focusing on new markets are two very important factors of creative activity in the development of tourist offer (Nelson et al., 2006), therefore, on that basis they are also an important factor for inter-destination cooperation the designers of the Slovenian project justifiably place it as an important activity in the project offer.

Third activity is creating a suitable business environment for the development of tourism in the region. Although that activity is mostly summed up in previous activities, and especially in the aims description, it is probably again introduced due to the nature of the project proposal. As it was previously pointed out, project proposal is in the context of the development of small and medium sized companies, which is obviously the focus of the authors of the proposal, rather than to display the complex needs of development in tourism. In any case, while creating a suitable business environment it is necessary to aim towards a wholesome partnership web and include in it the institutions of public, private and non-government sector, where small and medium sized business have a clearly important role, and it is also necessary to emphasize that they cannot complete that role without cooperating with other participants in the destination.

The biggest reprimand in the development of a project of this kind should be given to the almost complete neglect of the problems of tourist staff in inter-destination cooperation. Without cooperation in this area of development and the improvement of staff structure it is almost impossible to achieve true and actual development of inter-destination cooperation, especially in the context of the fact that on the level of Slovenia as a country there is no unified education system regarding staff in this area. Special emphasis should be placed on the fact that college education of tourist staff in Slovenia is a recent phenomenon, it exists on university level for less than 10 years, so serious conditions for in-depth research activity in this area could not yet be created. Thus, there are almost no known connections amongst government institutions, academic community (university), and tourist economy in a research project (Triple helix model). It seems that the youngest university in this area, one in Bežice, progressed the furthest in this by integrating even some experts from practice into their research teams.

Despite the numerous objects to this project, the fact is that it has, in a manner, enabled the following:

1. Awareness about the need of inter-destination cooperation within a wider tourist region.

2. Infrastructure for development in that direction (new organisational body, regardless that it will only exist virtually and not as a new segment of administrative structure). Namely, it is 
foreseen that a kind of management board (or steering committee) will be formed, which should manage and co-ordinate inter-destination activities and interests. It is unclear at the moment which tasks and responsibilities will be performed in this institution or body and to what extent. It would be expected that activities are those which are of common interest for all destination management organisations - DMO in the country as well as those which are in direction of international destination management matters and are beyond the capacity of each individual regional destination management organisation - RDO.

3. Completely different relation of the government administration towards the cooperation amongst various administrative organisational forms.

4. Attention of the academic community that, up until now, has not shown significant interest for the development of this complex area.

\section{Conclusion}

Inter-destination cooperation within a wider tourist region is a new means of strategic governing of the development of a tourist destination that should contribute to the advancement of tourist offer and to the creation of competitive advantage. Destinations that develop this cooperation are pioneers in the application of new models of regional development. Several examples of conducting inter-destination cooperation in practice can also encourage researchers in the area of tourism to work on developing theoretical bases for such cooperation. However, in this moment, scientific assistance to inter-destination cooperation is almost completely lacking, which can also be one of the reasons why inter-destination cooperation is still a rare sight. Deciding to establish cooperation amongst destinations is only the first step in their long journey to progress and does not in itself guarantee success. The efficiency of inter-destination cooperation stems from realistic market processes, and not only from the will of decision makers. Inter-destination cooperation is also a very promising area of future research.

The (rare) research that have been made until now on the topic of inter-destination cooperation shows that this problem is still insufficiently explained. Differences in motives and forms of inter-destination cooperation have been ascertained, however, a unique classification of factors of influence still does not exist. Special emphasis was placed on the analysis of determinants of such cooperation, and a large number of factors that primarily differ on the approach to research and applied identification criterions was determined. Generally speaking, four approaches are listed: analysis of cooperation determinants as prerequisites for cooperation, factors crucial for a successful development of cooperation, key personal abilities needed to govern cooperation in tourism, and factors of cooperation efficiency.

Research has been also been conducted in post-transitioning countries. The assumption of a "new institutional economy" (New Institutional Economics- NIE), where the rationality of an individual is rooted in social, historical and cultural context that consists of the so called official institutions (all legal norms related to given political and economic system), but also in the informal institutions (values, tradition, customs, history, culture etc.), seems to offer the 
best explanation why many processes in post-transitional countries proceed more slowly, even the cooperation of interest groups in the area of tourism. Namely, mechanical transfer of formal democratic institutions and market economy that functions well in developed market economies, is not accompanied by parallel changes in the informal institutions such as culture that support private property, set collective democratic actions in motion, encourage economic sensibility and rationality, and create trust of the environment. Precisely these informal institutions, determined by the way of thinking and behaviour of people, change very slowly and painstakingly in post-transitional countries, which represents a fundamental obstacle for inter and intra cooperation amongst tourist destinations and regions in those countries. Literature identifies numerous other factors that are an obstacle for such cooperation, such as the lack of positive examples to follow, adaptive (recreational) instead of proactive attitudes towards cooperation, underdeveloped civil society, financial problems of local governments, etc.

In the countries that succeeded former Yugoslavia, such as Serbia, Croatia and Slovenia, serious research in this area has not been made. In the tourist practice of these countries, there are no examples of complex inter-destination cooperation. Somewhat of an exception is the tourist region Istra in Croatia. In all other cases, only individual projects of regional cooperation were present, often motivated by other reasons, such as the development of entrepreneurship, new employment or moderating depopulation in a region, and not by advancement of tourist offer or by strengthening its competitiveness through inter-destination cooperation within a wider region. This can be explained by the fact that cooperation in the area of tourism in these countries has a short history, starting with the transformation of the economic system in the 1990s.

The basis of direct research consists of the content analysis of the document Long-term project of more intensive connecting of regional development organisations in Slovenia in the period of 2014-2020. This is the case of inter-destination cooperation mediated by the DMO. Project coordinator was the Slovenia Tourist Board. Although three very significant activities in project development were planned: (1) advancement of quality of existing and the development of new tourist products, (2) promotion and placement of tourist offer into the market, (3) creating suitable business environment for the development of tourism, according to the reduced content of the participants involved in this project it is justifiable to ask the question up to which degree it is possible to realise these tasks? The project was solidly constructed as a concept, but it lacks clarity in operative sense. Although the carrier of the project is addressed, they do not have a sufficiently defined coordination role, and it especially lacks clear mechanisms to gain and evaluate feedback. Problems encountered by particular destinations trying to establish and/or develop inter-destination cooperation are differentiated. However, the common conclusion is that organizational barriers are just as important as mental ones, which is strongly highlighted in the literature devoted to destination stakeholders' cooperation. Regardless of the numerous objections to this project, it can be stated that it provides a contribution to the development of consciousness about the need of inter-destination cooperation and the development of models for mediated cooperation that is led by management organisation of a destination - DMO, in this case 


\section{MInstitute Macrothink $_{\text {Int }}$}

International Journal of Regional Development ISSN 2373-9851

Slovenia Tourism Board, which is done amongst destinations as a part of development strategy of wider tourist region/country.

While it is clear that mediated inter-destination collaboration opens up an additional level of uncertainty, resource-based theories tend to emphasize the additional opportunities that inter-destination collaboration can bring to the organisations represented by the DMO. These might include enhanced market reach, greater ability to counteract local competition, adding complementarity to destination products and experiences, or the facilitation of more cost-effective marketing and promotional activities. The increasing turbulence and uncertainty in the wider environment and overall lack of linearity and stability merely enhance the need, and benefits to be achieved from mediated inter-destination collaboration. Where previously collaboration of such kind would have been viewed with trepidation because of the increasing risk and uncertainty involved, destination organisations at all levels are increasingly recognising the benefits of, and need for, more flexible, fleet-footed collaborative action. Collaboration is increasingly being identified as a valuable strategy for destinations to embrace. The introduction of a DMO is increasingly seen as an effective way of achieving collaboration among the various components making up the destination. At the same time, the DMO can also serve as a vehicle for collaborating with other destinations.

The area for further investigation is in conducting network analysis both within and across destinations. Future applications of network analysis should also pay attention to imitation and innovation processes both within and across destinations. Such research can deliver valuable knowledge for policy makers in developing governmental programs for the tourism industry. Collaboration allows destinations to expand their reach and tap into wider market opportunities but it also brings with it more risks and challenges related to the measurement, monitoring and the evaluation of performance.

\section{References}

Afonso, O., Monteiro, S., \& Thompson, M. (2010). A growth model forthe Quadruple Helix innovation theory. NIPE: University of MinhoWorking Paper Series, 12.

Baggio, R. (2008). Network analysis of a tourism destination. PhD Thesis. Brisbane, Australia: School of Tourism, The Univeristy of Queensland Brisbane.

Benur, A. M., \& Bramwell, B. (2015). Tourism product development and product diversification in destinations. Tourism Management, 50, 213-224.

Beritelli, P. (2011). Cooperation among prominent actors in a tourist destination. Annals of Tourism Research, 38(2), 607-629.

Beritelli, P., Bieger, T., \& Laesser, C. (2007). Destination governance: Using corporate governance theories as a foundation for effective destination management. Journal of Travel Research, 46(1), 96-107.

Beritelli, P., Bieger, T., \& Laesser, C. (2014). The new frontiers of destination management applying variable geometry as a function-based approach. Journal of Travel Research, 53(4), 403-417. 
Buhalis, D. (2000). Marketing the competitive destination of the future. Tourism Management, 21(1), 97-116.

Burns, R. (2000). Introduction to Research Methods. London: Sage.

Carlisle, Sh., Kunc, M., Jones, E., \& Tiffin, S. (2013). Supporting innovation for tourism development through multi-stakeholder approaches: Experiences from Africa. Tourism Management, 35, 59-69.

Cohen, W. M., \& Levinthal, D. A. (1990). Absorptive capacity: A new perspective on learning and innovation. Administrative Science Quarterly, 35, 128-152.

Creswell, J. D. (1994). Research design: Qualitative and quantitative approaches. Thousand Oaks, CA: Sage Publications.

Czernek, K. (2013). Determinants of cooperation in a tourist region. Annals of Tourism Research, 40, 83-104.

Del Chiappa, G., \& Baggio, R. (2015). Knowledge transfer in smart tourism destinations: analyzing the effects of a network structure. Journal of Destination Marketing \& Management (in press).

European Commission: Operational Programme for Cohesion Policy Funding 2014-2020. Retrieved from http://ec.europa.eu/regional_policy/EN/atlas/programmes/2014-2020/estonia/2014ee16m3op 001

Fyall, A., \& Garrod, B. (2005). Tourism marketing. A collaborative approach. Clevedon: Channel View Publications.

Fyall, A., Garrod, B., \& Wang, Y. (2012). Destination collaboration: A critical review of theoretical approaches to a multi-dimensional phenomenon. Journal of Destination Marketing \& Management, 1, 10-26.

Gunn, C. (1994). Tourism planning (3rd ed.). London: Taylor and Francis.

Hall, C.M. (1999). Rethinking collaboration and partnership: A public policy perspective. Journal of Sustainable Tourism, 7(3-4), 274-289.

Hall, C. M. (2005). Tourism: Rethinking the social science of mobility. Harlow: Prentice-Hall. Haugland, S.A., Ness, H., Gronseth, B., \& Aarstad, J. (2011). Development of tourism destinations-An Integrated Multilevel Perspective. Sven A. Haugland Annals of Tourism Research, 38(1), 268-290.

Henderson, J.C. (2001). Regionalisation and tourism: The Indonesia-Malaysia-Singapore growth triangle. Current Issues in Tourism, 4(2-4), 78-93.

Hjalager, A. M. (2010). A review of innovation research in tourism. Tourism Management, 31(1), 1-12. 
Horwath HTL Zagreb. (2013). Operativni priručnik za primenu modela destinacijske menadžment organizacije (DMO).

Hughes, Ch. (2015). Qualitative and quantitative approaches to social research. Retrieved from http://www.csse.monash.edu.au/ smarkham/ resources/ qual:htm

Hwang, Y. H., \& Fesenmaier, D. R. (2003). Multidestination pleasure travel patterns: Empirical evidence from the American Travel Survey. Journal of Travel Research, 42(2), 166-171.

Jegdić, V., \& Marković, D. (2010). Uspostavljanje međusektorskih partnerstava, okvir za jačanje konkurentnosti turizma Srbije. Marketing, 41(1), 43-52.

Mariani, M. M., Baggio, R., Buhalis, D., \& Longhi, C. (Eds.). (2014). Tourism management, marketing and development: the importance of networks and ICTs, New York: Palgrave.

Mariani, M. M., \& Kylanen, M. (2012). Inter-organizational relationships in time and space: coopetition in tourism destinations. Proceedings of the 2nd EIASM conference on tourism management and tourism related issues, France: Nice.

Ministrstvo za gospodarstvo, Direktorat za turizem. (2007). Razvojni načrt in usmeritve slovenskega turizma 2007-2011. Ljubljana.

Nacrt projekta: Povezovanje regionalnih destinacijskih organizacij 2014 - 2020.

Naipaul, S., Wang, Y., \& Okumus, F. (2009). Regional destination marketing: A collaborative approach. Journal of Travel \& Tourism Marketing, 26(5-6), 462-481.

Nelson, R. R., Mowery, D. C., \& Fagerberg, J. (Eds.), (2006). The Oxford handbook of innovation. Oxford: Oxford University Press.

Prideaux, B., \& Cooper, C. (2002). Marketing and destination growth: A symbiotic relationship or simple coincidence? Journal of Vacation Marketing, 9(1), 35-51.

Provan, K.G., Fish, A., \& Sydow, J. (2007). Interorganizational networks at the network level: A review of the empirical literature on whole networks. Journal of Management, 33(3), 479-516.

Puczko, L., Ratz, T., \& Smith, M. (2007). Old city, new image: Perception, positioning and promotion of Budapest. Journal of Travel and Tourism Marketing, 22(3-4), 21-34.

Roberts, L., \& Simpson, F. (2000). Developing partnership approaches to tourism in Central and Eastern Europe. In B. Bramwell, B. Lane (Eds.), Tourism collaboration and partnerships. Politics, practice and sustainability (230-247). Clevedon: Chanel View Publications.

Scott, N., Cooper, C., \& Baggio, R. (2008). Destination networks: four Australian cases. Annals of Tourism Research, 35(1), 169-188.

Scott, N. R., Cooper, C. P., \& Baggio, R. (2011). Use of network analysis in tourism research. In Advances in tourism marketing conference. Valencia: Publicacions de la Universitat de Valencia. 
Slovenska Turistička organizacija: Povezovanje regionalnih destinacijskih organizacij 2014-2020.

Slovenska Turistička organizacija: Razvojni načrt in usmeritve slovenskega turizma 2007-2011.

Stratigea, A., Papakonstantinou, D., \& Giaoutzi, M. (2008). ICTs and tourism marketing for regional development. In H. Coccosis \& J. Psycharis (Eds.), Regional Analysis and Policy The Greek Experience (pp. 315-333). Heidelberg: Springer Physica-Verlag.

Tosun, C. (2000). Limits to community participation in the tourism development process in developing countries. Tourism Management, 21(6), 613-633.

UNWTO. (2002). Destination Management \& Quality Programme: Conceptual Framework, 02-04.12.2002. Retrieved from http://destination.unwto.org/content/conceptual-framework-0

Vainikka, V. (2013). Rethinking mass tourism. Tourist Studies, 13(3), 268-286.

Van der Zee, E., \& Vanneste, D. (2015). Tourism networks unravelled; a review of the literature on networks in tourism management studies. Tourist Management Perspectives, 15, 46-56.

Wang, Y. (2008). Collaborative destination marketing: Understanding the dynamic process. Journal of Travel Research, 47, 151-166.

Wang, Y., Hutchinson, J., Okumus, F., \& Naipaul, S. (2013). Collaborative marketing in a regional destination: Evidence from central Florida. International Journal of Tourism Research, 15(3), 285-297.

Wood, D. J., \& Gray, B. (1991). Toward a comprehensive theory of collaboration. Journal of Applied Behavioral Science, 27(2), 139-162.

Yin, R. K. (1989). Case study research: Design and methods. Newbury Park, CA: Sage blication.

Zach, F., \& Racherla, P. (2011). Assessing the value of collaborations in tourism networks: A case study of Elkhart County, Indiana. Journal of Travel \& Tourism Marketing, 28(1), 97-110.

Zemla, M. (2010). Destination competitiveness and inter-organizational relations competitiveness paradigm. Challenges of application Service Management, 5, 249-263.

Zemla, M. (2014). Inter-destination cooperation: Forms, facilitators and inhibitors-The case of Poland. Journal of Destination Marketing \& Management, 3(2014), 241-252. 


\section{Copyright Disclaimer}

Copyright for this article is retained by the author(s), with first publication rights granted to the journal.

This is an open-access article distributed under the terms and conditions of the Creative Commons Attribution license (http://creativecommons.org/licenses/by/3.0/). 